\title{
EFEKTIVITAS REDEFINE RUMBAI OPTIMIZING SERVICE (RED ROSE) DI KANTOR KECAMATAN RUMBAI
}

\section{THE EFFECTIVENESS OF REDEFINE RUMBAI OPTIMIZING SERVICE (RED ROSE) AT THE RUMBAI DISTRICT OFFICE}

\author{
Pebriana Marlinda ${ }^{1}$, Yogi Yunefri ${ }^{2}$ \\ Universitas Lancang Kuning ${ }^{1,2}$ \\ pebriana@unilak.ac.id
}

\begin{abstract}
The rapid development of science and technology requires the government to improve the performance of public services, especially public services in the form of electronic services or E-services, so the government issued PERMENPAN RB RI Number 30 of 2014 concerning Guidelines for Public Service Innovation. This service innovation regulation requires local governments to compete in creating innovations in public services. Following up on regulations regarding service innovation, the Rumbai Regency Government presents an innovation in public services called Redefine Rumbai Optimizing Service or abbreviated as Red Rose. This application can manage information in the management of land documents in Rumbai District. The research method used is a qualitative approach, the analysis used is an interactive model in an interactive cycle in qualitative analysis is extension and continuity. From the results and discussion of the research, it is concluded that the Redefine Rumbai Optimizing Service (Red Rose) application has been running well, it's just not effective because this application has not directly involved the community in its use.
\end{abstract}

Keywords: Redefine Rumbai Optimizing Service, Public Service, Effectiveness.

Perkembangan ilmu pengetahuan dan teknologi yang sangat pesat menuntut pemerintah untuk meningkatkan kinerja pelayanan publik khususnya pelayanan publik berupa layanan elektronik atau Eservices, sehingga pemerintah mengeluarkan PERMENPAN RB RI Nomor 30 Tahun 2014 tentang Pedoman Inovasi Pelayanan Publik. Regulasi inovasi layanan ini menuntut pemerintah daerah berlombalomba menciptakan inovasi dalam pelayanan publik. Menindaklanjuti regulasi tentang inovasi pelayanan, Pemerintah Kabupaten Rumbai menghadirkan inovasi dalam pelayanan publik yang disebut Redefine Rumbai Optimizing Service atau disingkat Red Rose. Aplikasi ini dapat mengelola informasi dalam pengelolaan dokumen pertanahan di Kecamatan Rumbai. Metode penelitian yang digunakan adalah pendekatan kualitatif, analisis yang digunakan adalah model interaktif dalam siklus interaktif dalam analisis kualitatif adalah ekstensi dan kontinuitas. Dari hasil dan pembahasan penelitian diperoleh kesimpulan bahwa aplikasi Redefine Rumbai Optimizing Service (Red Rose) sudah berjalan dengan baik, hanya saja belum efektif karena aplikasi ini belum melibatkan masyarakat secara langsung dalam penggunaannya.

Kata Kunci: Redefine Rumbai Optimizing Service, Public Service, Effectiveness.

\section{PENDAHULUAN}

Perkembangan dunia saat ini berjalan sangat cepat yang dipengaruhi oleh perkembangan teknologi dan informasi yang sangat pesat di abad 21(Muqsith, 2021). Kondisini ini secara otomatis mempengaruhi berbagai aspek kehidupan masyarakat. Sehingga kebutuhan masyarakat menjadi berubah dan semakin meningkat level kebutuhannya yang dipicu oleh perkembangan teknologi dan informasi itu sendiri. Meningkatnya level kebutuhan masyarakat akan mempengaruhi pelayanan yang dibutuhkan oleh masyarakat dan mempengaruhi bentuk pelayanan yang diberikan oleh pemerintah sebagai pihak yang bertanggungjawab untuk 
memenuhi kebutuhan masyarakat juga akan berubah.

Mendapatkan pelayanaan publik yang layak merupakan hak seluruh warga negara yang harus dipenuhi oleh pemerintah. Terkait dengan ini pemerintah mengeluarkan kebijakan yaitu Undang-Undang Nomor 25 Tahun 2009 Tentang Pelayanan Publik (Saputra et al., 2019). Berdasarkan undangundang ini, pelayanan publik adalah kegiatan atau rangkaian kegiatan dalam rangka pemenuhan kebutuhan pelayanan sesuai dengan peraturan perundangan bagi setiap warga negara dan penduduk atas barang, jasa, dan/atau pelayanan administratif yang disediakan oleh penyelenggara pelayanan publik.

Sebagaimana yang telah dijelaskan sebelumnya bahwa kebutuhan masyarakat semakin meningkat yang dipicu oleh perkembangan teknologi dan informasi saat ini, mengaharuskan pemerintah untuk menyesuaikan bentuk dari pelayanan yang diberikan. Sehingga pemerintah mengeluarkan PERMENPAN RB RI Nomor 30 Tahun 2014 Tentang Pendoman Inovasi Pelayanan Publik(Menpan, 2013). Hadirnya peraturan ini mengharuskan pemerintah daerah agar berpacu untuk menciptakan inovasi - inovasi dalam pelayanaan publik.

Menindak lanjuti peraturan tentang inovasi pelayanan tersebut, maka Pemerintah Kecamatan Rumbai mengahadirkan sebuah inovasi dalam pelayanan publik yang diberi nama Redefine Rumbai Optimizing Service dan disingkat dengan RedRose. Aplikasi pelayanan ini dibuat sebagai solusi dari permasalahn pelayanan publik yang terjadi di Kecamatan Rumbai. Adapun permasalahan yang terjadi di Kecamatan Rumbai yaitu :

1. Masih banyak masyarakat yang tidak memiliki surat tanah, sehingga sering terjadi sengketa tanah.
2. Banyaknya terjadi tumpang tindih kepemilikan tanah, sehingga pihak Kecamatan sering kali terlibat masalah hukum.

3. Masih banyaknya daerah-daerah di Kecamatan Rumbai yang tidak tersentuh pembangunan, sehingga terjadinya kecemburuan social.

Kondisi ini lah yang mengharuskan pemerintah Kecamatan Rumbai Untuk mencari solusi dari permasalahan tersebut. Sehingga aplikasi Red Rose ini dipilih sebagai solusinya.

\section{Inovasi Pelayanan Publik}

Sedarmayanti dalam Maron (2015) menyatakan bahwa inovasi meliputi penciptaan sesuatu yang tidak ada saat ini dan dapat berupa penciptaan kecil atau sesuatu yang monumental. inovasi sukses memiliki lima karakteristik berikut: cukup baru bagi pasar; Berdasarkan teknologi yang telah diteli dan dites; menghemat uang pengguna inovasi; memenuhi kebutuhan pelanggan; mendukung praktek yang ada. Robbins dalam Djamrut (2015) memfokuskan inovasi pada 3 (tiga) hal utama yaitu:

1. Gagasan baru yaitu suatu olah pikir dalam mengamati suatu fenomena yang sedang terjadi, termasuk dalam bidang pendidikan, gagasan baru ini dapat berupa penemuan dari suatu gagasan pemikiran, ide, sistem sampai pada kemungkinan gagasan yang mengkristal.

2. Produk dan jasa yaitu hasil langkah lanjutan dari adanya gagasan baru yang ditindak lanjuti dengan berbagai aktivitas, kajian, penelitian dan percobaan sehingga melahirkan konsep yang lebih konkret dalam bentuk produk dan jasa yang siap dikembangkan dan diimplementasikan termasuk hasil inovasi dibidang pendidikan. 
3. Upaya perbaikan yaitu usaha sistematis untuk melakukan penyempurnaan dan melakukan perbaikan yang terus menerus sehingga buah inovasi itu dapat dirasakan mafaatnya.

Menurut Yogi dalam LAN (2007), ditinjau secara lebih khusus, pengertian inovasi dalam pelayanan publik bisa diartikan sebagai prestasi dalam meraih, meningkatkan dan memperbaiki efektivitas, efisiensi dan akuntabilitas pelayanan publik yang dihasilkan oleh inisiatif pendekatan, metodologi dan atau alat baru dalam pelayanan masyarakat.

Pemerintah Kecamatan Rumbai mengambil sebuah langkah dalam rangka mewujudkan pelayanan publik yang baik dan sesuai dengan masanya dengan sebuah terobosan baru yaitu RED ROSE (Redefine Rumbai Optimizing Service). RED ROSE ini merupakan sebuah aplikasi pelayanan publik pada bidang pertanahan. Munculnya RED ROSE ini bertujuan agara pelayanan publik di Kecamatan Rumbai dapat terlaksana dengan efektif dan efisien.

\section{Efektivitas}

Menurut Gibson, "Efektivitas adalah pencampaian tujuan dan sasaran yang telah disepakati untuk mencapai tujuan usaha bersama. Tingkat tujuan dan sasaran itu menunjukkan tingkat efektivitas. Tercapainya tujuan dan sasaran itu akan ditentukan oleh tingkat pengorbanan yang telah dikeluarkan".

Steers dalam Tangkilisan (2005) ukuran efektivitas (1985:53) adalah sebagai berikut:

1. Pencapaian Tujuan

Pencapaian adalah keseluruhan upaya pencapaian tujuan harus dipandang sebagai suatu proses. Oleh karena itu, agar pencapaian tujuan akhir semakin terjamin, diperlukan pentahapan, baik dalam arti pentahapan pencapaian bagian-bagiannya, maupun pentahapan dalam arti periodisasinya. Pencapaian tujuan terdiri dari beberapa faktor, yaitu: Kurun waktu dan sasaran yang merupakan target kongkrit.

2. Integrasi

Integrasi yaitu pengukuran terhadap tingkat kemampuan suatu organisasi untuk mengadakan sosialisasi, pengembangan konsensus dan komunikasi dengan berbagai macam organisasi lainnya. Integrasi menyangkut proses sosialisasi.

3. Adaptasi

Adaptasi adalah kemampuan organisasi untuk menyesuaikan dengan lingkungannya. Untuk itu digunakan tolak ukur proses pengadaan dan pengisian tenaga kerja.

\section{METODE}

Penelitian ini menggunakan metode deskriptif pendekatan kualitatif. Penelitian ini mendiskripsikan data yang diperoleh dari hasil penelitian mengenai implementasi kebijakan inovasi pelayanan publik di puskesmas jaya mukti dalam meningkatkan kepuasan masyarakat. Data dihimpun dengan pengamatan yang seksama, mencangkup deskripsi dalam konteks yang mendetil disertai catatancatatan hasil wawancara yang mendalam, serta hasil analisis dokumen dan catatan(Pérez \& Santamaria, 2017).

Miles dan Humbermen (2017) menjelaskan analisis data adalah proses menyusun dan menggabungkan data ke dalam pola, tema, kategori, sedangkan penafsiran adalah memberikan makna kepada analisis, menjelaskan pola atau kategori, dan mencari hubungan antara beberapa konsep. Penafsiran menggambarkan perspektif peneliti bukan kebenaran. Analisis dan penafsiran data dalam penelitian kualitatif pada dasarnya bukan 
merupakan hal yang berjalan bersama, keduanya dilakukan sejak awal penelitian. Analisis data dilakukan agar data yang telah diperoleh akan lebih bermakna. Analisis data merupakan proses penyederhanaan data kedalam bentuk yang lebih mudah dibaca dan diinterprestasikan.

Miles dan Humbermen (2017) menjelaskan analisis data adalah proses mencari secara sistematis dan mengatur catatan wawancara, catatan lapangan, dan rider lain yang dihimpun untuk menggiring pengertian. Analisis tersebut melibatkan kerja dengan data, mengaturnya, memisahkan kedalam unit-unit yang dapat dikelola, memadukannya, mencari-cari pola memenuhi hal-hal penting dan apa yang diketahui dan memutuskan apa yang akan disampaikan kepada orang lain. Analisis data penelitian ini, bila dinyatakan dalam bentuk gambar adalah sebagai berikut:

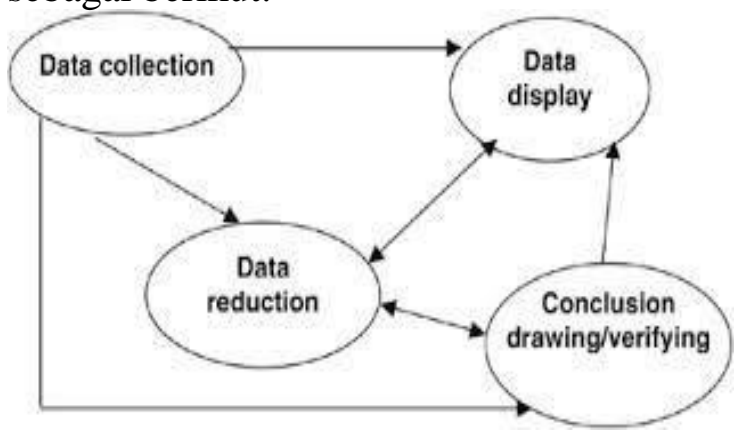

Gambar 1. Analisis Data Penelitian. Sumber : Milles dan Huberman dalam Pebriana (2018).

Tahap-tahap tersebut merupakan kegiatan yang harus diperhatikan dalam analisis data kualitatif. Kegiatan pengumpulan data, reduksi data, penyajian dan penarikan kesimpulan/verifikasi dalam analisis model interaktif merupakan siklus interaktif dalam pengertian analisis kualitatif merupakan upaya yang berlanjut, berulang dan terus menerus.
HASIL DAN PEMBAHASAN

1. Efektivitas Redefine Rumbai Optimizing Service (Red Rose) di kantor kecamatan rumbai.

Kecamatan merupakan salah satu Organisasi Perangkat Daerah di daerah yang mempunyai tugas membantu Kepala Daerah dalam penyelenggaraan pemerintahan di Kecamatan. Kecamatan memiliki peran dalam upaya menyusun kebijakan dan program pembangunan di Kecamatan secara optimal sesuai dengan dinamika dan tuntutan masyarakat yang berkembang dan pelaksanaan otonomi di daerah.

Berdasarkan pada pasal 7 ayat (1) dan Pasal 15 ayat (3) Undangundang Nomor 25 Tahun 2004 tentang Sistem Perencanaan Pembangunan Nasional dinyatakan bahwa Kepala Satuan Kerja Perangkat Daerah menyiapkan rancangan Renstra-SKPD, yang memuat Visi, Misi, Tujuan, Strategi, Kebijakan, Program dan Kegiatan Pembangunan yang disusun sesuai dengan Tugas Pokok dan Fungsi Satuan Kerja Perangkat Daerah. Sesuai dengan ketentuan tersebut diatas, Kecamatan Rumbai menyusun Rencana Strategis (Renstra) Tahun 2018-2022 dengan tujuan sebagai berikut :

1) Sebagai landasan operasional untuk menggerakkan seluruh sumber daya Kecamatan, sehingga seluruh unsur dan stakeholder dapat diberdayakan secara optimal melalui keterpaduan dalam program.

2) Menyediakan suatu acuan resmi bagi aparatur Kecamatan dalam menentukan prioritas program lima tahunan dan kegiatan tahunan serta menyediakan indikator-indikator yang 
dijadikan tolok ukur dalam melakukan evaluasi capaian kinerja terhadap pelaksanaan program dan kegiatan.

3) Memudahkan seluruh jajaran aparatur Kecamatan dalam mencapai tujuan, disamping juga bertujuan untuk menumbuhkan komitmen aparatur Kecamatan dengan cara menyusun program dan kegiatan secara terpadu, terarah dan berkelanjutan.

4) Memudahkan seluruh jajaran aparatur Kecamatan untuk memahami dan memulai arah kebijakan dan program serta kegiatan operasional tahunan dalam rentang waktu 5 (lima) tahun.

Menjadi acuan dan pedoman pelaksanaan dalam merealisasikan rencana yang berkaitan dengan tugas pokok dan fungsi SKPD, sehingga pencapaiannya dapat dilakukan dengan lebih efisien dan efektif.

\section{Pencapaian Tujuan}

Dalam sebuah organisasi tujuan merupakanacuan ataupun sesuatu yang harus dicapai. Melalui program redrose pihak pemerintahan Kecamatan Rumbai ingin melakukan penertiban hak kepemilikan tanah di Kecamatan Rumbai. Berhubung Kecamatan rumbai ini merupakan kecamatan pinggiran kota yg masih banyak terdapat lahan kosong yang hak kepemilikannya masih belum jelas. Adanya aplikasi redros ini diharapkan dapat membantu pencatatan atau pendaftaran hak kepemilikan tanah secara benar sehingga tidak terjadi hal-hal yang tidak diinginkan dikemudian hari seperti sengketa tanah dll dan kami pun sebagai pihak pemerintah menjadi lebih lama.

Kehadiran aplikasi Red Rose ini bertujuan untuk mengaman posisi kepemerintahan sebagai pejabat yang menandatangani surat tanah masyarakat, sehingga dikemudian hari tidak terjadi hal-hal yang tidak diinginkan. Kantor Kecamatan Rumbai sebagai bagian dari tatanan pemerintahan wajib memberikan pelayanan publik kepada masyarakat. Berikut ini indicator tujuan dan sasaran jangka menengah pelayanan Kecamatan Rumbai dapat dilihat pada tabel berikut ini.

Tabel 1.1 Target Indikator Tujuan dan Sasaran Jangka Menengah Pelayanan Kecamatan Rumbai.

\begin{tabular}{|c|c|c|c|}
\hline No & Tujuan & Sasaran & Indikator Sasaran \\
\hline 1 & 2 & 3 & 4 \\
\hline \multirow{2}{*}{1.} & \multirow{2}{*}{$\begin{array}{l}\text { Mewujudkan } \\
\text { Pelayanan Prima }\end{array}$} & $\begin{array}{l}\text { Meningkatkan Pelayanan } \\
\text { Publik di Kecamatan }\end{array}$ & $\begin{array}{l}\text { Indeks pelayanan/indeks } \\
\text { kepuasan masyarakat }\end{array}$ \\
\hline & & $\begin{array}{l}\text { Meningkatkan Kapasitas } \\
\text { dan Akuntabilitas Kinerja } \\
\text { Birokrasi }\end{array}$ & $\begin{array}{l}\text { Nilai Akuntabilitas Kinerja } \\
\text { Kecamatan (AKIP) }\end{array}$ \\
\hline 2. & $\begin{array}{l}\text { Mewujudkan } \\
\text { Pemberdayaan } \\
\text { Masyarakat } \\
\text { dalam } \\
\text { Pembangunan }\end{array}$ & $\begin{array}{l}\text { Meningkatnya } \\
\text { pemberdayaan masyarakat } \\
\text { dalam Pembangunan }\end{array}$ & $\begin{array}{l}\text { Persentase Partisipasi } \\
\text { Lembaga Masyarakat dalam } \\
\text { Pembangunan }\end{array}$ \\
\hline
\end{tabular}

Sumber : Renstra Kecamatan Rumbai

Dari tabel 1.1 diatas dapat diketahui bahwa ada 2 tujuan jangka menengah pelayanan Kecamatan Rumbai yaitu : mewujudkan pelayanan prima dan mewujudkan pemberdayaan masyarakat dalam pembangunan. Aplikasi Red Rose merupakan salah satu bentuk program untuk mewujudkan tujuan dari pelayanan public di Kecamatan Rumbai.

Dalam setiap program yang dilaksanakan oleh pemerintah itu memiliki sasaran dari program tersebut. Begitu juga dengan program pelayanan publik yang dilaksanakan oleh pemerintah Kecamatan Rumbai melalui aplikasi Red Rose. Sasaran program red rose ini tentu saja masyarakat yang memiliki lahan atau memiliki tanah. 
Sebagaimana yang telah saya sampaikan tadi bahwa Kecamatan rumbai ini merupakan kecamatan pinggiran kota yg masih banyak terdapat lahan kosong yang hak kepemilikannya masih belumjelas. Selain itu aplikasi Red Rose ini juga berfungsi untuk pemetaan suatu wilayah. Jadi dengan adanya redrose ini dikemudian hari masyarakat tidak bisa mengklem lahannya tampa bukti. Selain itu dengan adanya redrose ini memudahkan pihak Kecamtan untuk melihat daerahdaerah yang pembangunannya masih belum maksimal atau daerah-daerah yang belum tersentuh pembangunan seperti jalanan yang rusah dan lampu penerangan yang tidak ada atau rusak. Hanya saja kelemahan dari aplikasi ini menurut peneliti yaitu aplikasi ini tidak bisa langsung digunakan oleh masyarakat langsung. Namun dari aspek pihak kecamatan dalam melaksanakan atau menyelesaikan tugas mereka tentu sangat memberikan keuntungan. Berikut hasil wawancara peneliti dengan pegawai Kantor Kecamatan Rumbai.

Keuntungan yang didapatkan sebagai pihak pemerintah tentu saja banyak, tapi yang paling penting dan utama keuntungan yang saat ini dirasakan yaitu dengan adanya aplikasi redrose ini yaitu menghindari kami tersandung kasus hukum karena sebagai pihak yang menandatangani surat kepemilikan tanah dari masyarakat. Karena dari kasus-kasus sebelum adanyanya aplikasi redrose ini banyak munculnya kasus sengketa tanah sehingga pejabat yang menandatangangi surat kepemilikan tanah tersebut dipanggil pihak kepolisian. Red Rose ini merupakan program jangka panjang di
Kecamatan Rumbai. Hal ini mengingat fungsi serta dampak mafaat yang muncul dengan adanya aplikasi ini. Kemungkinan untuk dihilangkan tentu saja tidak, tapi untuk dilakukan pengembangan seiring dengan kemajuan teknologi dan tuntutan kebutuhan zaman tentu saja

\section{Integrasi}

Organisasi pada hakikatnya bersifat dinamis menyesuaikan keadaan ataupun zaman. Begitu juga dengan pelayanan public. Diera perkembangan teknologi yang begitu pesat dan mendominasi hampir disegala aspek termasuk dalam tatanan pemerintahan salah satunya pelayanan public. Red Rose sebagai sebuah program yang menggunakan aplikasi teknologi informasi yang diharapkan mampu membantu pelaksanaan tatanan kepemerintahan di Kecamatan Rumbai.

Awal kemunculan aplikasi redrose ini pihak kecamatan melakukan sosialisasi kepada pegawai kecamatan sendiri tentunya dan pihak kelurahan yang ada di lingkungan pemerintah Kecamatan Rumbai. Sosialisasi yang kami lakukan berupa pelatihan dalam rangka pengenalan aplikasi redrose itu sendiri. Pelatihan diikuti oleh pegawai kecamatan dan pegawai kelurahan beserta pimpinan. Disamping it, ada pihak-pihak lain yang terlibat yaitu pihak kelurahan, kecaamtan rumbai, pemerintahan kota pekanbaru dan BPN Kota Pekanbaru. Pihak - pihak inilah yang terlibat dalam pelaksanaan redrose di Kecamatan Rumbai. Karena pngajuan awal itu dilakukan oleh pihak kelurahan

\section{Adaptasi}

$\begin{array}{ccc}\text { Adaptasi } & \text { dalam } & \text { hal ini } \\ \text { maksudnya } & \text { adalah } & \text { kondisi }\end{array}$


lingkungan yang terkait dengan pelaksanaan Red Rose ini. Dimana pada saat awal kemunculan aplikasi redrose ini tentu saja banyak pihak akan merasa asing, apapun itu sesuatu yang baru akan sering mendapatkan penolakan pada awal kemunculannya. Penolakan atau kendala itu muncul dari pihak masyarakat. Karena pada awalnya mereka merasa aplikasi ini merepotkan mereka. Namun berlahan setelah beberapa tahun ketika mereka mulai merasakan manfaatnya. Pada saat penolakan itu terjadi pihak kecamatan terus menerus melakukan pendekatan terhadap masyarakat agar mereka paham dan nyaman dengan aplikasi ini.

Pengenalan aplikasi ini tidak hanya kepada masyarakat sebagai sasaran utama dalam program ini, tetapi juga pengenalan kepada para pegawai sebagai pihak pelaksana dari aplikasi ini. Pada tahap awal agar pegawai memahami dan mampu menggunakan aplikasi redrose ini tentu saja dengan diberikannya pelatihan-pelatihan kepada pegawai Kantor Kecamatan Rumbai. Disamping itu pelatihan juga diberikan kepada pihak kelurahan, hal ini dilakukan karena pihak kelurahan juga meupakan pihak yang terlibat dalam penggunaan aplikasi ini.

\section{SIMPULAN}

Adapun kesimpulan yang dapat Dari hasil dan pembahasan penelitian maka peneliti membuat kesimpulan bahwa: Redefine Rumbai Optimizing Service (RED ROSE) sudah berjalan dengan baik, hanya saja belum efektif dikarenakan aplikasi ini belum belibatkan masyarakan langsung dalam penggunaannya.

\section{DAFTAR PUSTAKA}

Djamrut, D. E. (2015). Inovasi Pelayanan Publik di Kecamatan Sungai Kunjang Kota Samarinda. Jurnal Ilmu Pemerintahan, 3(3), 1472-1486.

Firdaus, R. (2019). Efektivitas Pelayanan Administrasi Di Rumah Sakit Umum Daerah (Rsud) I Lagaligo Kabupaten Luwu Timur. Journal I La Galigo| Public Administration Journal, 2(2), 6171.

Scott, G. M. (2004). Prinsip-prinsip sistem informasi manajemen.

Gibson, J. L., Invancevich, J. M., \& Donnelly, J. H. (2001). Organisasi, terjemahan Agus Dharma. Erlangga, Jakarta.

Hardiyansyah, H. (2018). Kualitas Pelayanan Publik: Konsep, Dimensi, Indikator dan Implementasinya. Gava Media.

Hartono, J. (2000). Pengenalan Komputer: dasar ilmu komputer, pemrograman, sistem informasi dan intelegensi buatan. Yogyakarta: Andi Offset.

Tangkilisan, H. N. S. (2005). Manajemen publik. Grasindo.

Marom, A. (2015). Inovasi Birokrasi Pelayanan Publik Bidang Sosial Tenaga Kerja dan Transmigrasi di Kabupaten Kudus. GEMA PUBLICA: Jurnal Manajemen dan Kebijakan Publik, 1(1), 4563.

Menpan.

(2013).

Menteri pendayagunaan aparatur negara dan reformasi birokrasi republik indonesia. 2008(1), 1-2.

Miles, M. B., Huberman, A. M., \& Saldaña, J. (2018). Qualitative data analysis: A methods sourcebook. Sage publications.

Muqsith, M. A. (2021). Teknologi Media Baru: Perubahan Analog Menuju 
Digital. ADALAH, 5(2).

Saputra, T., Marlinda, P., Sufi, W., \&

Kuning, U. L. (2019). Implementasi

Kebijakan Inovasi Pelayanan

Publik. Niara, 11(2), 177-184

Siagian, S. P. (2002). Kiat meningkatkan produktivitas kerja. Jakarta: Rineka Cipta.

Pérez, A., \& Santamaria, E. K. (2017). Introduction to Data Analysis in Qualitative Research. $B M C$ Public Health, 5(1), 1-8. 